\title{
OBSERVATIONAL ANALYSIS OF TWO CONTRASTING MONSOON YEARS
}

\author{
Srinivasarao Karri*, Ramiz Ahmad, Sujata P, Subin Jose, Sreenivas G and Devesh Kumar Maurya
}

Atmospheric and Climate Sciences Group (ACSG), Earth and Climate Science Area (ECSA), NRSC, Hyderabad, India

KEY WORDS: Indian Summer Monsoon, OLR and AOD

\begin{abstract}
:
The Indian summer monsoon rainfall contributes about $75 \%$ of the total annual rainfall and exhibits considerable interannual variations. The agricultural economy of the country depends mainly on the monsoon rainfall. The long-range forecast of the monsoon rainfall is, therefore of significant importance in agricultural planning and other economic activities of the country. There are various parameters which influence the amount of rainfall received during the monsoon. Some of the important parameters considered by the Indian Meteorological Department (IMD) for the study of monsoon are Outgoing Longwave Radiation (OLR), moisture content of the atmosphere, zonal wind speed, low level vorticity, pressure gradient etc.

Compared to the Long Period Average (LPA) value of rain fall, the country as a whole received higher amount of rainfall in June, 2013 (34\% more than LPA). The same month showed considerable decrease next year as the amount of rainfall received was around $43 \%$ less compared to LPA. This drastic difference of monsoon prompted to study the behaviour of some of the monsoon relevant parameters. In this study we have considered five atmospheric parameters as the indicators of monsoon behaviour namely vertical relative humidity, OLR, aerosol optical depth (AOD), wind at $850 \mathrm{hPa}$ and mean sea level pressure (MSLP).

In the initial analysis of weekly OLR difference for year 2013 and 2014 shows positive values in the month of May over north-western parts of India (region of heat low). This should result in a weaker monsoon in 2014. This is substantiated by the rainfall data received for various stations over India. Inference made based on the analysis of RH profiles coupled with AOD values is in agreement with the rainfall over the corresponding stations.
\end{abstract}

\section{Introduction}

The word "monsoon" is derived from the Arabic word for season and is traditionally defined as a seasonally reversing wind system accompanied by seasonal changes in atmospheric circulation and precipitation (Gadgil, 2003). The Indian monsoon is driven by asymmetric heating between the cooler Indian Ocean and the warmer Indo-Asian landmasses (Kelkar, 2012). For India, southwest monsoon (June to September) is more important as it accounts for over $75 \%$ of the annual rainfall in most parts of India (Parthasarathy et al., 1987). Understanding of the Indian summer monsoon (ISM) is an important and difficult challenge for the research community. The year-to-year variations of the precipitation has a strong impact on the food production, water resources and the whole economy in one of the most populated areas in the world (Parthasarathy et al., 1988, 1992). The interannual variation of the ISM Rainfall (ISMR) is highly correlated with the global teleconnections. According to the 1st stage forecast of the IMD, the monsoon rainfall in 2014 is likely to be less than the long term average. The expected occurrence of an undesirable phenomenon - the El Niño over the Pacific Ocean, is considered to be a major factor in

* Corresponding Author: Srinivasarao Karri, Atmospheric and Climate Sciences Group, Earth and Climate Science Area, NRSC, Hyderabad, India. E-Mail: srinivasmet@gmail.com, Contact: 040-20388-4231 determining the fate of the monsoon this year. Apart from global teleconnections there are various parameters, which influence the amount of rainfall India receives during the monsoon. Some of the important parameters considered by the Indian Meteorological Department (IMD) for the study of monsoon are zonal wind speed, low level vorticity, moisture content of the atmosphere, pressure gradient etc. (Monsoon Report, 2013).

Compared to the Long Period Average (LPA) value of rain fall, the country as a whole received higher amount of rainfall in June, 2013 (34\% more than LPA). The same month showed considerable decrease next year as the amount of rainfall received was around 43\% less compared to LPA as shown in figure.1. This drastic difference of monsoon prompted to study the behavior of some of the monsoon relevant parameters. In this study we have considered five atmospheric parameters as the indicators of monsoon behavior namely Mean Sea Level Pressure (MSLP), vertical relative humidity, OLR, wind at $850 \mathrm{hPa}$ and aerosol optical depth (AOD).

Traditionally OLR has been used for radiation budget studies of the earth-atmosphere system. Recently it has been used for atmospheric circulation studies over the tropics since in these regions OLR is largely modulated by cloud top temperature, and low OLR generally 
indicates convective systems, whereas high OLR is generally from cloud free regions indicating high surface temperature (Prasad et al., 2000 and Gadgil et al., 2003). In particular it varies with the cloud top temperature and hence low radiation values indicate major convective systems. Quantitatively, values less than $250 \mathrm{Wm}-2$ gives a good indication of cloudiness over the tropics (Prasad and Verma, 1984).

During the pre-monsoon months OLR may be used as a proxy to estimate the development of heat low over the North-Western India and Eastern regions of Pakistan. Depending on its intensity, heat low either enhances or decreases the strength of low level jet known as "Findlater Jet", or "Somali Jet". This is a relatively narrow wind stream at $850 \mathrm{hPa}$ level along the coast of Somalia over the Indian Ocean and peninsular India (Joseph and Raman (1966), Findlater (1969 a and b)). The Low Level Jet is the northern branch of a crossequatorial flow Speeds usually ranging between 10 to 15 $\mathrm{m} / \mathrm{s}$ in the Arabian Sea, which provides the major amount of moisture for the ISM.

The monsoonal rainfall is associated with high degree of convective activities at lower level of troposphere, due to which the vertical distribution of moisture changes. Since the atmospheric moisture significantly increases before the onset of the monsoon along Kerala coast as it advances to cover the Indian region, vertical profiles of humidity works as an indicator of convective clouds, which may lead to rainfall. Aerosols affect rainfall by changing radiation exchanges in the atmosphere and at the surface (direct effect) (Kaufman et al., 2002), or by its interaction with clouds (indirect effect), and by other geophysical-chemical-dynamical processes, such as changing wind speed or chemical interactions (Jacobson and Kaufman, 2006).

\section{Data and Methodology}

For the present study, we have used observational data stets from both in-situ measurements and remote sensing data from various satellite sensors. The weekly averaged rainfall data was prepared from daily rainfall data was acquired from IMD AWS stations. Weekly averaged OLR data was obtained from high resolution Indian geostationary weather satellite KALPANA-1 sensor Very High Resolution Radiometer (VHRR) over the Indian region $\left(0^{\circ}-40^{\circ} \mathrm{N}, 60^{\circ}-100^{\circ} \mathrm{E}\right)$ in a regular grid of 0.25 $\times 0.25$ degrees. Relative humidity was obtained from SAPHIR, a microwave humidity sounder on-board Megha Tropiques having frequencies around $183.31 \mathrm{GHz}$ for six atmospheric layers from the surface to nearly 12 $\mathrm{km}$. Both SAPHIR and VHRR data were downloaded from the MOSDAC website. The NCEP/NCAR reanalysis wind data at $850 \mathrm{hPa}$ pressure level (Kalnay et al 1996) is used to examine the circulation features associated with the normal and deficit monsoon conditions. The aerosol optical depth at $550 \mathrm{~nm}$ obtained from Daily MODIS data is used. MSLP data obtained from NCEP/NCAR reanalysis to examine the intensity of heat low.

A comparative study was carried out between the data sets of 2013 and 2014 for the selected parameters. Based on the comparison, we made several observations which are discussed in the next section.

\section{Observations}

A first-hand look at the rainfall data for the country in June shows a considerable deviation from the normal pattern of the monsoon. Year 2013 received excess rainfall for almost entire country except for the NorthEastern states. Whereas in year 2014 for the same month the situation is very different compared to 2013 with hardly any area receiving normal rainfall. The Eastern and North Western India and the Southern states of Kerala, Karnataka and Telangana all received deficient amount whereas there was scant rainfall in the Western part of India including states of Gujarat, Maharashtra, Western Madhya Pradesh, Eastern Rajasthan, Uttarakhand and Western Uttar Pradesh. This shows that either monsoon was late or has been very weak. Since the onset of monsoon along the Kerala coast was on time we can conclude that the monsoon has been weak, the reasons for which could be found by the analysis of various parameters which affects its strength.

The OLR difference between year 2013 and 2014 for the month of May shows positive values in the Western and North Western part of country and over the Eastern Pakistan (figure.2). This means that the heat low was well developed in May 2013, but was weak in 2014. The pressure difference plot for mean sea level pressure (figure.3) reflects the pattern of OLR. In the region of intense heat low, the difference value of MSLP for two years is of the order of 3-4 mbar. The effect of strong and weak heat low or development of high (2014) and low (2013) pressure area is directly reflected in the strength of the low level jets (850 hpa) over the Arabian Sea. As observed in the wind plots (figure.4), for June 2013 there was strong jet flow from Arabian Sea towards the Indian land mass. The intensity of jet increases from first to third week of June where it maximizes. And though the central part of the flow weakens slightly in the fourth week of the month, the wind for the most past is strong having values in the excess of $15 \mathrm{~m} / \mathrm{s}$.

The intensity trend followed by the low level jet formed during June is very similar to that of OLR anomaly with a lag of one month. As is evident from the OLR anomaly plot between May 2013 and 2014, the anomaly over the North Western India and Eastern Pakistan maximizes during the third week of May and then decreases in the fourth.

The strong low level jet formed during June brings the moisture from sea to the land surface where it helps in the formation of clouds leading to rainfall. Because of 
weak heat low in 2014, the lower level jets were weak as well, hence there was insufficient transfer of moisture from sea to land resulting in weaker monsoon.

The other factor which affects the amount of rainfall is aerosol. Presence of right sized aerosol in the atmosphere works as CCN (cloud condensation nuclei) around which the cloud grows. High value of humidity favors the formation of cloud. The AOD value in the years of study has similar distribution with slight difference in its values. Hence no discernible relation was observed between the rainfall and the value of AOD.

The amount of rainfall received at various stations corroborates well with the value of humidity. A comparison between the humidity profiles of various stations for the study years agrees well with the amount of rainfall received. Almost all the stations under study received higher amount of rainfall during 2013 compared to 2014. This is reflected in the vertical profiles of humidity of those stations. For all the stations the value of relative humidity in 2014 is 20-25 units less than that of 2013, especially at the lower levels of atmosphere. For example, for Hyderabad, the plot of RH profile for two years very clearly brings out this difference (data was not available for the third week of June, 2013) (figure.5).

\section{Conclusions}

During June, 2013 rainfall activity over the country as a whole was very good, whereas June, 2014 received considerably less amount of rainfall. Difference in monsoon behavior in successive years has prompted a study to analyze pre-monsoon and monsoon conditions in terms of a few parameters as indicators. The comparative study of two contrasting monsoon years showed appreciable difference in the parameters like OLR, RH and low level wind. For a deficient year in the premonsoon month value of these parameters decreased compare to an excess June rainfall. These parameters thus could serve as some of the possible indicators of strength of the monsoon. However no relation was found between the amount of rainfall and the value of AOD. This could because AOD affects the monsoon in a more complicated way than we were able to observe.

Further study could be carried out for other consecutive contrasting monsoon years to see if the chosen parameters follow similar trend.

\section{Acknowledgments}

Authors are thankful to Dr. P.V.N.Rao Group Director, ACSG for initiation of the work and his valuable suggestions. We are also thankful to
CDAS/ASAD/NRSC for providing the rainfall data from their archives, IMD for spatial rainfall maps, NCEP/NCAR for reanalysis data and MOSDAC for MEGATROPIQUES and KALPNA-1 data.

\section{Reference}

Findlatter. J., (1969), A major air current near the west Indian Ocean during the northern summer, Quart. JRoy. Meteorol. Soc., 95, 1251-1262.

Gadgil. S., (2003), The Indian monsoon and its variability, Earth Planet. Sci. 31:429-67

Gadgil. S., Vinayachandran. P. N., and Francis, P. A., (2003), Droughts of the Indian summer monsoon: Role of clouds over the Indian Ocean, Current Science, vol. 85, 12-25.

Jacobson. M. Z., and Kaufman Y. J., (2006), Wind reduction by aerosol particles, Geophys. Res. Lett., 33, L24814, doi:10.1029/2006GL027838.

Joseph, P. V. and Raman, P. L., (1966), Existence of low level westerly jet stream over Peninsular India during July. Ind. J. Met. Geophys., 17,407-410.

Kaufman, Y. J., D. Tanre, and Boucher. O., (2002), A satellite view of aerosols in the climate system, Nature, 419, 215-223.

Kalnay E, Kanamitsu M, Kistler R, Collins W and coauthors (1996), The NCEP/NCAR 40-year reanalysis project; Bull. Am. Meteor. Soc. 77, 437-471.

Kelkar, R.R., (2012), Monsoon elsewhere in the world, Monsoon Monograph, Volume1

Monsoon Report-2013, IMD

Prasad, K.D. and Verma, R.K., (1985), Large scale features of satellite-derived outgoing longwave radiation in relation to monsoon circulation over Indian region, J. Climatol., 5, 297-306.

Prasad, K.D., Bansod. S.D. and Sabade. S.S., (2000), Forecasting Indian Summer Monsoon Rainfall by Outgoing Longwave Radiation over the Indian ocea, Int. J. Climatol. 20: 105-114

Parthasarathy, B., Sontakke. N. A., Munot. A. A. and Kothawale. D. R., (1987), Droughts/floods in summer monsoons season over different meteorological subdivisions of India for the period 1871-1980; J. Climatol., 7, 57-70.

Parthasarathy, B., A. A. Munot and Kothawale, D. R., (1988), Regression model for estimation of foodgrain production from summer monsoon rainfall. Agric. Forest Meteorol., 42, 167-182.

Parthasarathy, B., Rupa Kumar, K. and Munot, A.A., (1992) Forecast of rainy-season food grain production based on monsoon rainfall, Indian J.Agricul. Sci., 62, 18. 
Figures
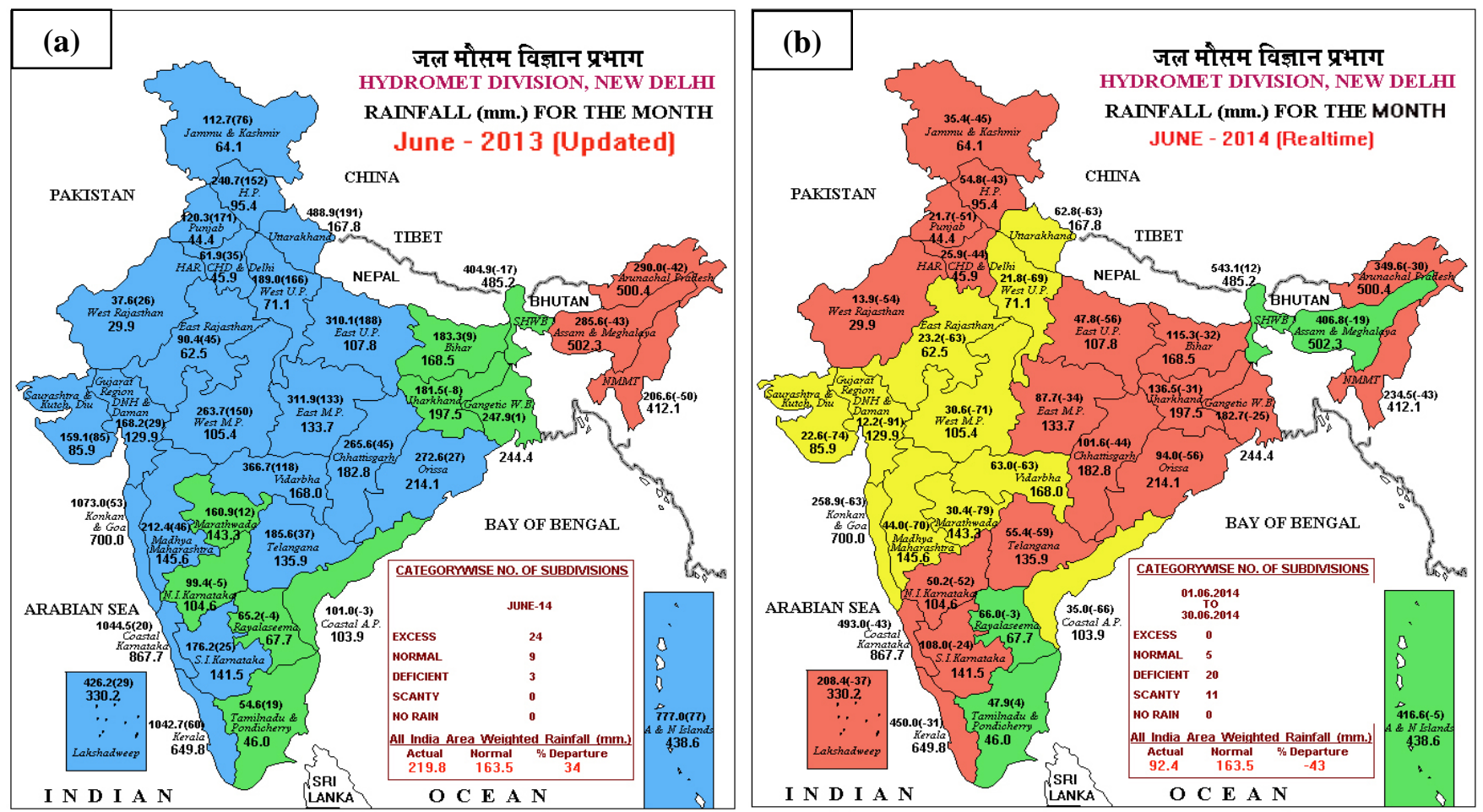

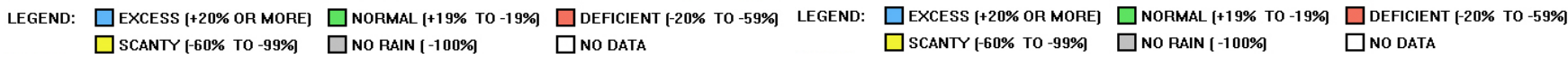

Figure.1. Rainfall (mm) distribution over India for the month of June in (a) 2013 and (2) 2014 [IMD, www.imd.gov.in]
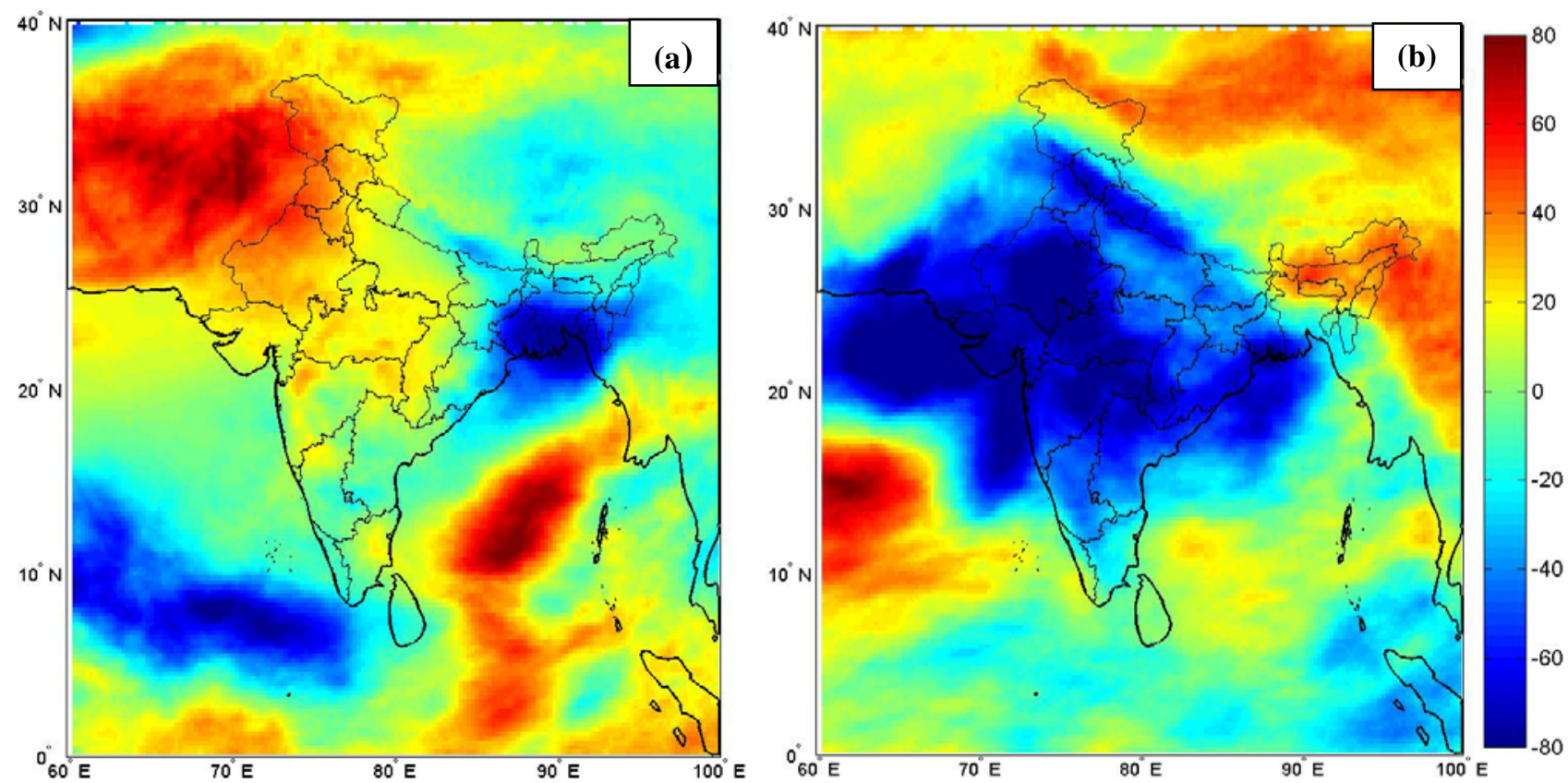

Figure.2. KALPANA-1 Weekly OLR difference between 2013-2014 (W/m²) for (a) 3rd Week of May and (b) 2nd week of June 


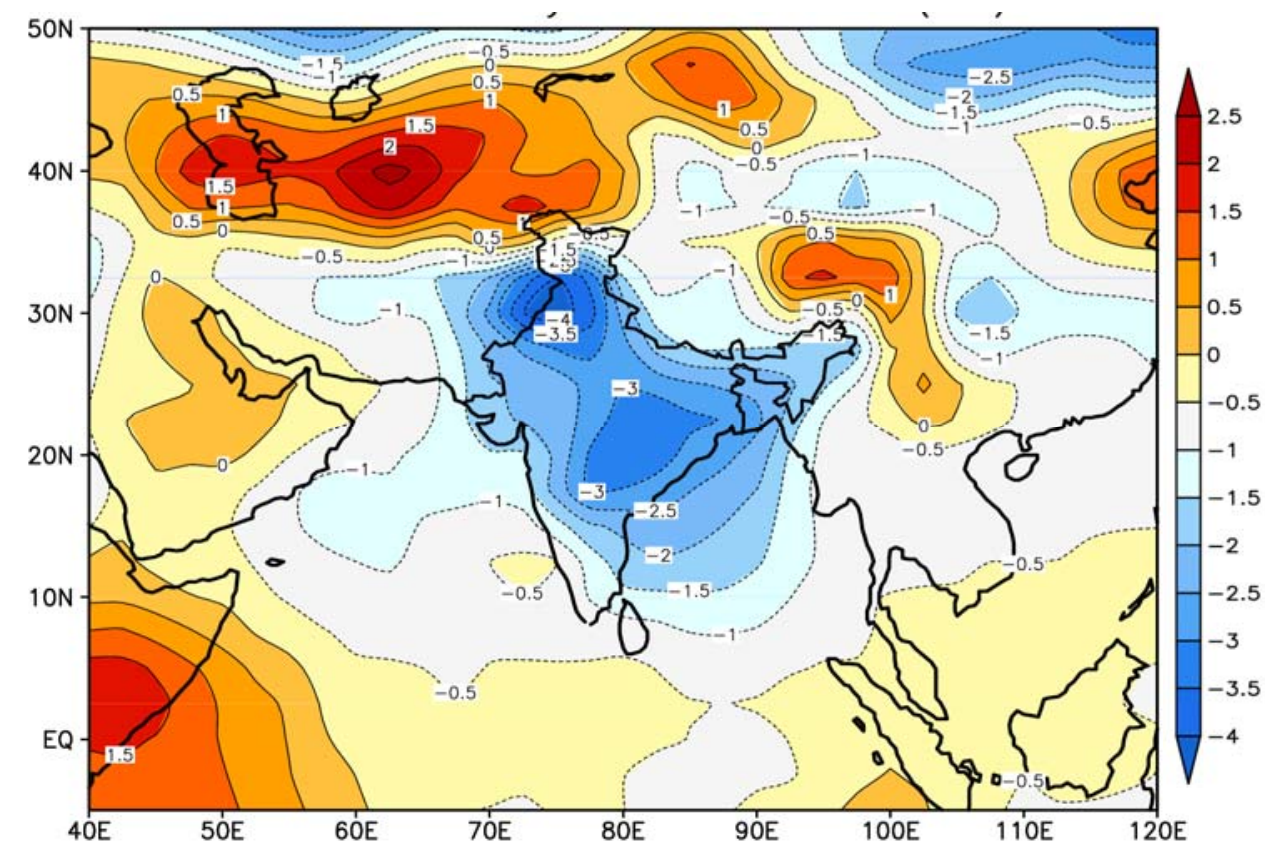

Figure.3. NCEP/NCAR reanalysis Mean Sea Level Pressure difference (mb) between 2013-2014 for the month of May
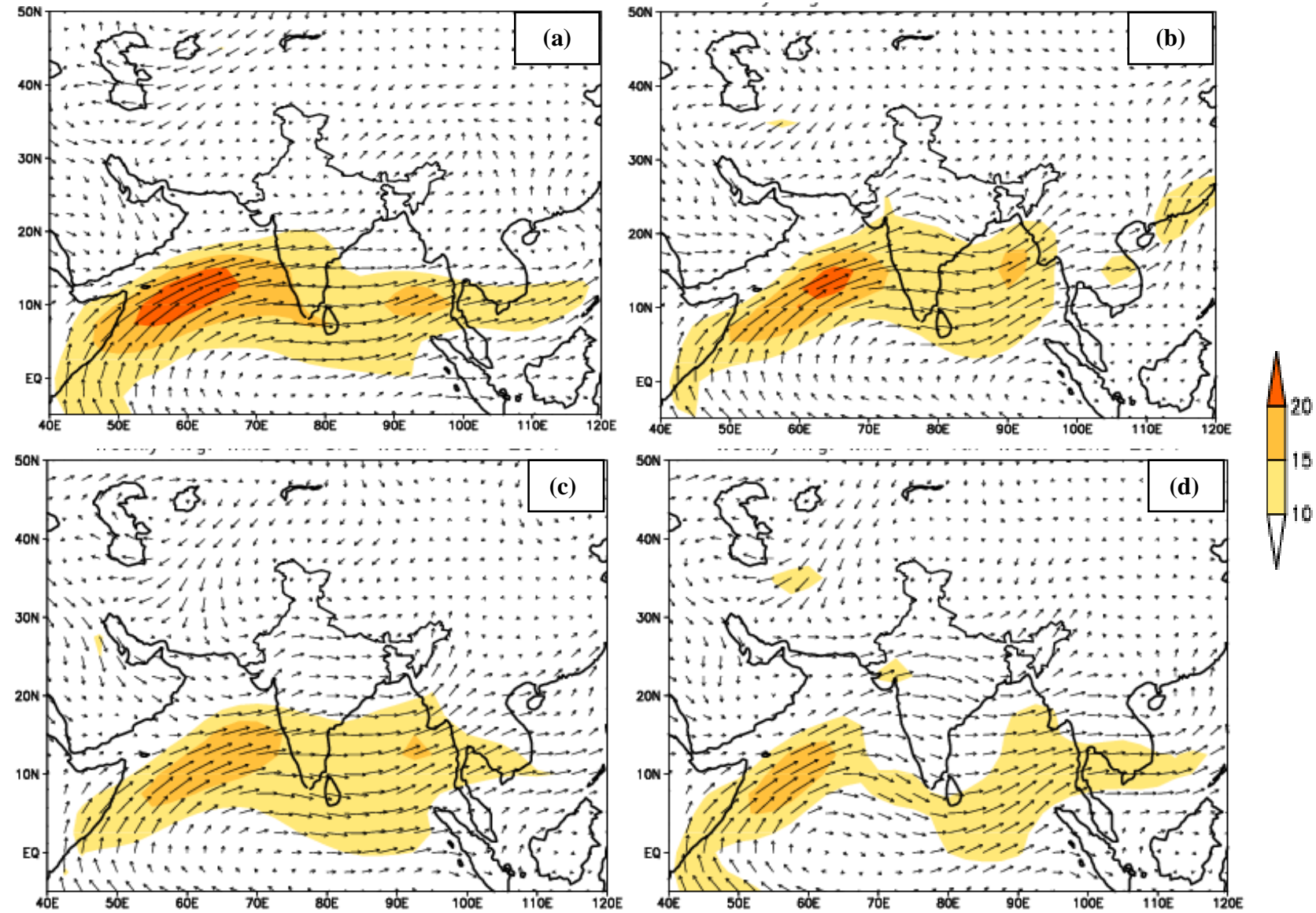

Figure.4. NCEP/NCAR reanalysis Weekly $850 \mathrm{hPa}$ Wind (m/s) for June 2013 (a) 3rd and (b) 4th and for June 2014 (c) 3rd and (d) 4th 


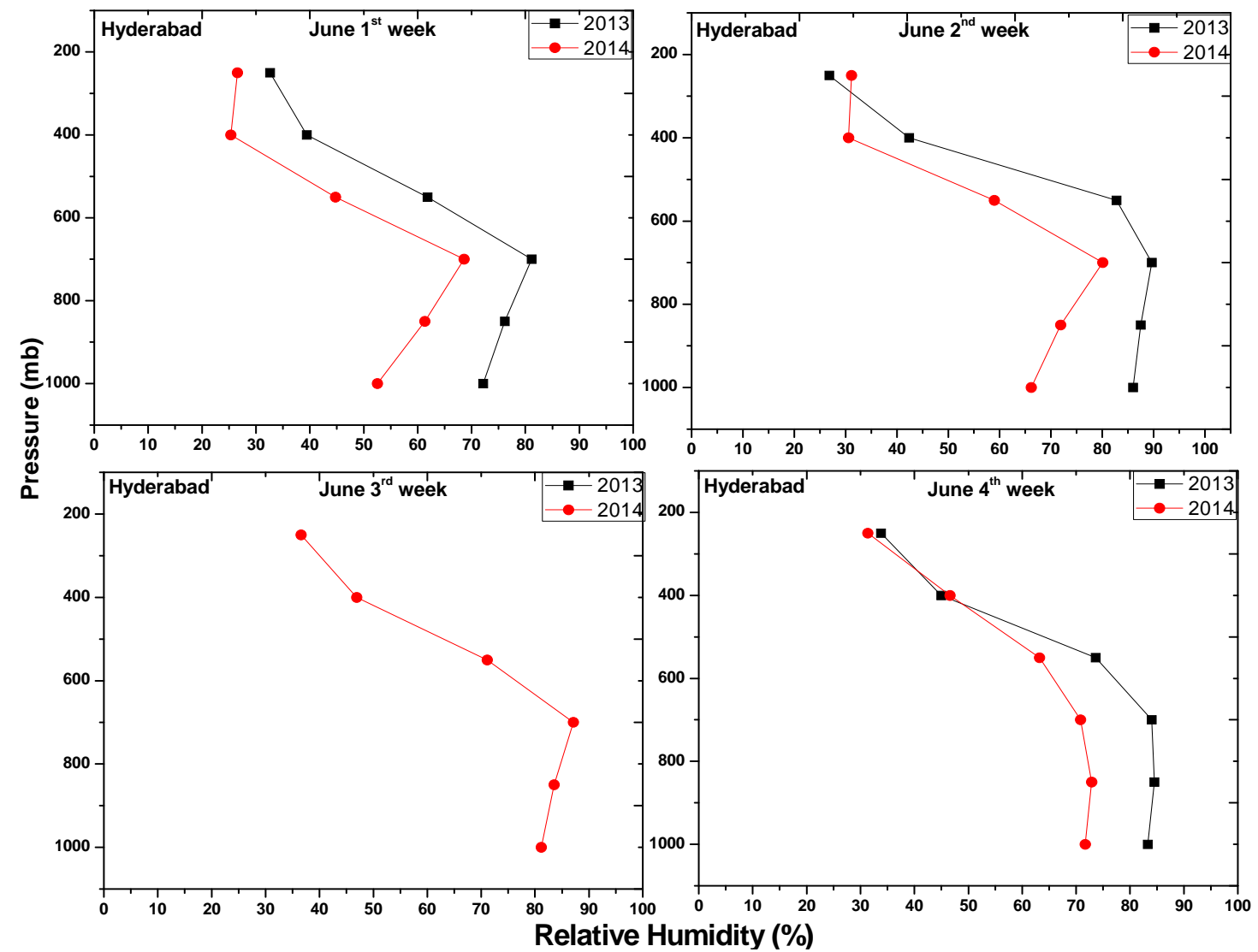

Figure.5. SAPHIR Relative Humidity profiles (\%) for June 2013 and 2014 